\title{
Water gas may not shift under extreme conditions of pressure and temperature
}

\author{
Nore Stolte, ${ }^{1, *}$ Junting Yu, ${ }^{1, *}$ Zixin Chen, ${ }^{2}$ Dimitri A. Sverjensky, ${ }^{3}$ and Ding Pan $^{1,2,4, \dagger}$ \\ ${ }^{1}$ Department of Physics, Hong Kong University \\ of Science and Technology, Hong Kong, China \\ ${ }^{2}$ Department of Chemistry, Hong Kong University \\ of Science and Technology, Hong Kong, China \\ ${ }^{3}$ Department of Earth and Planetary Sciences, Johns Hopkins University, \\ 3400 North Charles Street, Baltimore, MD 21218, USA \\ ${ }^{4}$ HKUST Fok Ying Tung Research Institute, Guangzhou, China
}

(Dated: January 15, 2021)

\begin{abstract}
The water-gas shift reaction is a key reaction in Fischer-Tropsch-type synthesis, which is widely believed to generate hydrocarbons in the deep carbon cycle, but is little known at extreme pressuretemperature conditions found in Earth's upper mantle. Here, we performed extensive ab initio molecular dynamics simulations and free energy calculations to study the water-gas shift reaction. We found the direct formation of formic acid out of $\mathrm{CO}$ and supercritical water at 10 13 GPa and $1400 \mathrm{~K}$ without any catalyst. Contrary to the common assumption that formic acid or formate is an intermediate product, we found that $\mathrm{HCOOH}$ is thermodynamically more stable than the products of the water-gas shift reaction above $3 \mathrm{GPa}$ and at 1000 1400 K. Our study suggests that the water-gas shift reaction may not happen in Earth's upper mantle, and formic acid or formate may be an important reduced carbon carrier, participating in many geochemical processes in deep Earth.
\end{abstract}




\section{INTRODUCTION}

Carbon is a unique element for all known life on Earth. Its oxidation state varies from -4 to +4 , which gives it very rich chemical bonding environments. More than $90 \%$ of Earth's carbon is stored in its interior [1], and the deep carbon cycle substantially influences climate change over geologic time and human energy consumption near Earth's surface, with a critical impact on human sustainable development [2]. Although as early as the 19th century, Mendeleev proposed that petroleum might be formed by abiogenic means [3], only over the past few decades have scientists started to seriously evaluate the possibility of hydrocarbon generation from subducting carbon and water in the deep carbon cycle $[4,5]$. Hydrocarbons may play a key role in the formation of diamonds [6-9], the possible origin of abiogenic petroleum [5] and even deep life [10]; however, the formation of hydrocarbons is little known at extreme conditions found in Earth's upper mantle, where pressure $(\mathrm{P})$ may reach $\sim 13$ GPa and temperature (T) as high as $1700 \mathrm{~K}[11,12]$.

Fischer-Tropsch-type synthesis, which converts inorganic carbon to organic matter, has been widely believed to naturally happen in deep Earth environments $[4,5]$, but most of our knowledge is limited to industrial applications, where P-T conditions are not as severe as in Earth's interior and purpose-designed catalysts are crucial [13]. In Fischer-Tropsch-type processes, the water-gas shift reaction is a key reaction to balance the $\mathrm{CO} / \mathrm{H}_{2}$ ratio [14]:

$$
\mathrm{CO}(\mathrm{g})+\mathrm{H}_{2} \mathrm{O}(\mathrm{g}) \rightleftharpoons \mathrm{CO}_{2}(\mathrm{~g})+\mathrm{H}_{2}(\mathrm{~g})
$$

This reaction is exothermic $(-41 \mathrm{~kJ} / \mathrm{mol}$ at $0.1 \mathrm{MPa}$ and $298 \mathrm{~K})$, but has a large reaction barrier, so industry usually uses transition metal catalysts, e.g, Fe-Cr and Cu-Zn, at aboveambient conditions: 1-6 MPa and 450-720 K [15]. The reaction mechanism varies with different catalysts, but industrial catalysts usually do not exist in deep Earth [4]. Some studies suggest that formic acid $(\mathrm{HCOOH})$ or formate $\left(\mathrm{HCOO}^{-}\right)$may be a possible reaction intermediate in the catalyzed [16] and uncatalyzed [17] reactions. Sharma et al. started experiments from formic acid to study $\mathrm{C}-\mathrm{H}-\mathrm{O}$ fluids in a reducing environment, and found 
that $\mathrm{HCOOH}$ fully decomposes into $\mathrm{CO}_{2}, \mathrm{H}_{2}, \mathrm{CO}$, and $\mathrm{H}_{2} \mathrm{O}$ when $\mathrm{P}$ is lower than $0.5 \mathrm{GPa}$ and $\mathrm{T}$ is above $623 \mathrm{~K}[18]$.

$\mathrm{C}-\mathrm{H}-\mathrm{O}$ fluids in the deep crust and upper mantle are a fundamentally important carbon carrier in the deep carbon cycle, and were traditionally modeled as simple mixtures of small volatile molecules, e.g. $\mathrm{H}_{2} \mathrm{O}, \mathrm{CO}_{2}, \mathrm{CO}, \mathrm{CH}_{4}, \mathrm{H}_{2}$ [19]. Recently, experimental and theoretical studies have started to consider aqueous ions, complexes, and chemical speciation in C-H-O fluids [8, 20-25], and many of them focus on fully oxidized carbon forms in supercritical water [26-29]. With increasing depth, Earth's interior becomes more reducing [30], so reduced carbon is of great importance in deep Earth, but due to the lack of reliable data at extreme PT conditions, the water-gas shift reaction was simply assumed to adjust the fluid composition in a reducing environment $[18,31]$.

Here, by performing extensive ab initio molecular dynamics (AIMD) simulations, we studied mixtures of $\mathrm{CO}$ and $\mathrm{H}_{2} \mathrm{O}$ and reaction products at extreme $\mathrm{P}-\mathrm{T}$ conditions found in Earth's upper mantle. Without any empirical input, AIMD simulations have grown to be powerful tools to predict chemical speciation at extreme conditions from first principles [32], and many predictions were confirmed by later experiments (e.g., [21, 26-28]). We found that CO directly reacts with $\mathrm{H}_{2} \mathrm{O}$ to generate formic acid at $10 \sim 13 \mathrm{GPa}$ and $1400 \mathrm{~K}$ without any catalyst. Contrary to the assumption that formic acid or formate will finally decompose, our free energy calculations suggest that formic acid is thermodynamically more stable than the mixture of $\mathrm{CO}_{2}$ and $\mathrm{H}_{2}$ above $3 \mathrm{GPa}$ and at 1000 1400 K. Our study suggests that the water-gas shift reaction may not happen in Earth's upper mantle, and formic acid or formate may be an important carbon carrier in $\mathrm{C}-\mathrm{H}-\mathrm{O}$ fluids in a reduced environment, which participates in many geochemical processes in the deep carbon cycle, such as waterrock interactions and diamond formation in the mantle. Our findings highlight the diversity of aqueous carbon species in $\mathrm{C}-\mathrm{H}-\mathrm{O}$ fluids and the importance of organic geochemistry at extreme conditions. 


\section{RESULTS}

We first dissolved 0.93 molal carbon monoxide $(\mathrm{CO})$ into supercritical water at $\sim 10$ and 13 GPa, $1400 \mathrm{~K}$, the P-T conditions as found at the bottom of Earth's upper mantle. Fig. 1 shows the mole percents of carbon-containing species as functions of simulation time in AIMD simulations. At $\sim 10 \mathrm{GPa}, \mathrm{CO}(\mathrm{aq})$ reacted with water to become formic acid $(\mathrm{HCOOH}(\mathrm{aq}))$ after about $200 \mathrm{ps}$ :

$$
\mathrm{CO}(\mathrm{aq})+\mathrm{H}_{2} \mathrm{O} \rightarrow \mathrm{HCOOH}(\mathrm{aq})
$$

We continued the simulation up to 330 ps and found that $\mathrm{HCOOH}(\mathrm{aq})$ dissociated frequently; the main solutes were the $\mathrm{HCOOH}(\mathrm{aq})$ molecule and the formate ion $\left(\mathrm{HCOO}^{-}(\mathrm{aq})\right)$. When pressure was increased to $\sim 13 \mathrm{GPa}, \mathrm{CO}(\mathrm{aq})$ reacted with water faster, after only $\sim 30$ ps. In the following $~ 300$ ps simulation, we found again that $\mathrm{HCOOH}(\mathrm{aq})$ and $\mathrm{HCOO}^{-}(\mathrm{aq})$ were the two major carbon species in the solution. At $\sim 13 \mathrm{GPa}$, it is also interesting to see formation of a minor carbon species, orthoformic acid $\left(\mathrm{HC}(\mathrm{OH})_{3}(\mathrm{aq})\right.$ shown in Fig. S1 in the supporting information), whose mole percent in total dissolved carbon was $\sim 2 \%$. The orthoformic acid molecules were formed by the reaction between $\mathrm{HCOOH}(\mathrm{aq})$ and water, and then rapidly dehydrated to become $\mathrm{HCOOH}(\mathrm{aq})$ via a reaction involving multiple water molecules within 2 ps.

To study the formation mechanism of aqueous formic acid (Fig. 2), we carried out 6 AIMD simulations from uncorrelated initial configurations at $\sim 10$ and $~ 13$ GPa, $1400 \mathrm{~K}$ (see Table SI in the supporting information). We found that the CO molecule and a few water molecules in solvation shells participated in the reaction. The carbon atom in the CO molecule formed a new $\mathrm{C}-\mathrm{O}$ bond with an oxygen atom from a $\mathrm{H}_{2} \mathrm{O}$ molecule or $\mathrm{OH}^{-}$ion. Within less than 100 fs this carbon atom also received a proton donated from a $\mathrm{H}_{3} \mathrm{O}^{+}$ion or another $\mathrm{H}_{2} \mathrm{O}$ molecule to form a C-H bond. When the new $\mathrm{C}-\mathrm{O}$ bond formed between the CO molecule and a $\mathrm{H}_{2} \mathrm{O}$ molecule, the extra proton transferred to the solvent water molecules along hydrogen bond wires. When the new $\mathrm{C}-\mathrm{H}$ bond formed between the $\mathrm{CO}$ molecule 
and a $\mathrm{H}_{2} \mathrm{O}$ molecule, the remaining hydroxide ion either simply moved away or diffused by accepting a proton from neighboring water molecules. Overall, we found that the intense proton transfer and solvation interactions play a key role to generate $\mathrm{HCOOH}(\mathrm{aq})$. The reaction mechanism is fundamentally different from that in the gas phase, where $\mathrm{HCOOH}(\mathrm{g})$ was considered as an intermediate in the water-gas shift reaction and only up to three water molecules participated [33].

The almost simultaneously formed C-O and C-H bonds never broke after the formic acid molecule was generated, but $\mathrm{HCOOH}(\mathrm{aq})$ had very frequent acid dissociation reactions:

$$
\mathrm{HCOOH}(\mathrm{aq}) \rightleftharpoons \mathrm{HCOO}^{-}(\mathrm{aq})+\mathrm{H}^{+}(\mathrm{aq})
$$

The dissociation constant, $K_{a}$, depends on P-T conditions as shown in Fig. 3. With increasing pressure at $1000 \mathrm{~K}$ or $1400 \mathrm{~K}, K_{a}$ increases, while with increasing temperature along an isobar, $K_{a}$ decreases. The trend of change is correlated with the variance of the dielectric constant of supercritical water, $\epsilon_{0}$, as shown by previous first-principles and machine learning studies $[21,34] . \epsilon_{0}$ increases with $\mathrm{P}$ and decreases with $\mathrm{T}$, so the formate ion and proton are easier to separate with increasing $\mathrm{P}$, but more difficult to separate with increasing T. At ambient conditions, formic acid is a weak acid with $1.3 \%$ of $\mathrm{HCOOH}(\mathrm{aq})$ dissociating [35], whereas at $\sim 13 \mathrm{GPa}$ and $1400 \mathrm{~K}$, our AIMD simulations showed that $\sim 62$ $\%$ of $\mathrm{HCOOH}(\mathrm{aq})$ became ions. The predicted importance of the formate ion at elevated temperatures and pressures is consistent with recent aqueous speciation-solubility models of upper mantle fluids [23].

The proton in reaction (3) kept hopping back and forth between formate and its surrounding water molecules in our simulations. Fig. 4 shows the radial distribution functions (RDFs) of the carbon atom of formate versus oxygen atoms of water $\left(\mathrm{O}_{w}\right)$ or hydronium $\left(\mathrm{O}_{\mathrm{H}_{3} \mathrm{O}^{+}}\right)$at 10 and $13 \mathrm{GPa}$, and $1400 \mathrm{~K}$. All RDFs have the main peaks at $\sim 3.1 \AA$, corresponding to the first solvation shells of formate. The first peak of the $\mathrm{C}-\mathrm{O}_{\mathrm{H}_{3} \mathrm{O}^{+}} \mathrm{RDF}$ is taller than the first peak of the $\mathrm{C}-\mathrm{O}_{\mathrm{H}_{2} \mathrm{O}} \mathrm{RDF}$ at both $\sim 10$ and $\sim 13 \mathrm{GPa}$, indicating that 
the $\mathrm{H}_{3} \mathrm{O}^{+}(\mathrm{aq})$ ion tends to reside in the first solvation shell of $\mathrm{HCOO}^{-}(\mathrm{aq})$. With increasing pressure from $\sim 10$ to $\sim 13 \mathrm{GPa}$, the first peak of the $\mathrm{C}-\mathrm{O}_{\mathrm{H}_{3} \mathrm{O}^{+}}$RDF becomes lower, because the dielectric constant of water increases [21, 34], which weakens the ion pairing strength between $\mathrm{HCOO}^{-}(\mathrm{aq})$ and $\mathrm{H}_{3} \mathrm{O}^{+}(\mathrm{aq})$.

In the industrial water-gas shift reaction, the products are $\mathrm{CO}_{2}$ and $\mathrm{H}_{2}$, and formic acid is considered as an intermediate in some reaction mechanisms. Our longest AIMD trajectory is about $340 \mathrm{ps}$, which is quite long as a first-principles simulation, but may be too short considering the reaction kinetics, so formic acid may decompose into $\mathrm{CO}_{2}$ and $\mathrm{H}_{2}$ later. To assess the thermodynamic stability of formic acid, we also studied the possible reaction between $\mathrm{CO}_{2}$ and $\mathrm{H}_{2}$ at extreme P-T conditions. In a simulation box, we mixed $20 \mathrm{CO}_{2}$ molecules and $20 \mathrm{H}_{2}$ molecules. At $\sim 13 \mathrm{GPa}$ and $1400 \mathrm{~K}$, we did not see any chemical reaction in a simulation nearly 300 ps long, whereas after increasing temperature to $2000 \mathrm{~K}$ and $2400 \mathrm{~K}$ at $\sim 14 \mathrm{GPa}$, we found the formation of formic acid again:

$$
\mathrm{CO}_{2}+\mathrm{H}_{2} \rightarrow \mathrm{HCOOH}
$$

We continued the simulation for another $\sim 150$ ps, and saw no further reaction of HCOOH. In $\mathrm{CO}_{2}$ capture and storage, the hydrogenation of $\mathrm{CO}_{2}$ to formic acid usually occurs in the presence of catalysts [36], while our AIMD simulations show that the uncatalyzed reaction is possible at extreme P-T conditions.

Big molecules tend to break at high temperatures because a mixture of small molecules has a larger entropy $(S)$ and the entropy term $(-T S)$ in the Gibbs free energy dominates. However, when increasing temperature from $1400 \mathrm{~K}$ to $2000 \mathrm{~K}$ along an isobar, formic acid, a relatively larger molecule, can be spontaneously synthesized from $\mathrm{CO}_{2}$ and $\mathrm{H}_{2}$, indicating that it is an enthalpically driven reaction. At the lower temperature of $1400 \mathrm{~K}$, the entropy term contributes less than at $2000 \mathrm{~K}$, so the formation of formic acid should be even more favored. The reason we did not see formic acid in our AIMD simulation at $1400 \mathrm{~K}$ is that the reaction kinetics is slow and our simulation is not long enough. 
To infer the possible P-T range for the formation of formic acid, We calculated the free energies of formic acid and the mixture of $\mathrm{CO}_{2}$ and $\mathrm{H}_{2}$ using the two-phase thermodynamic model [37-39] To validate our calculation method, we first compared the free energies of the reactants and products of the water-gas shift reaction at $\sim 10 \mathrm{MPa}$ and $473 \mathrm{~K}$. The reaction enthalpy change $(\Delta H)$ is $-59.8 \pm 1.8 \mathrm{~kJ} / \mathrm{mol}, T \Delta S$ is $-1.0 \pm 2.2 \mathrm{~kJ} / \mathrm{mol}$, and the free energy change $(\Delta G)$ is $-58.8 \pm 2.8 \mathrm{~kJ} / \mathrm{mol}$, so the forward water-gas shift reaction is exothermic and thermodynamically favored, consistent with experimental findings. Spanu et al. applied the two-phase thermodynamic model to study the formation of heavier alkanes from methane, and found that the mixtures of longer alkanes and hydrogen are thermodynamically more stable than methane when $\mathrm{P}$ is above $4 \mathrm{GPa}$ and $\mathrm{T}$ is between 1000 and $2000 \mathrm{~K}$ [40]. Our test and the previous study suggest that the two-phase thermodynamic model is capable to evaluate thermodynamic stability of C-H-O fluids at high P-T conditions.

We then increased pressure to $10 \mathrm{GPa}$ and temperature to 1000 and $1400 \mathrm{~K}$ to calculate the free energy of reaction (4), as shown in Fig. 5. We found that the mixture of $\mathrm{CO}_{2}$ and $\mathrm{H}_{2}$ is thermodynamically more favored than formic acid up to $\sim 0.8 \mathrm{GPa}$ at $1000 \mathrm{~K}$. At higher pressures, reaction (4) may happen spontaneously. With increasing $\mathrm{P}$ along an isotherm, the reaction enthalpy becomes more negative, while the entropy term, $T \Delta S$, does not vary much, so formic acid becomes thermodynamically more stable than the mixture of $\mathrm{CO}_{2}$ and $\mathrm{H}_{2}$. When increasing temperature to $1400 \mathrm{~K}$ along an isobar, the free energy of reaction (4) becomes less negative, and formic acid is more favored when $\mathrm{P}>\sim 2.7 \mathrm{GPa}$. Our free energy calculations show that reaction (4) is exothermic and enthalpically driven.

In our AIMD simulations, we mainly used the generalized gradient approximation exchange-correlation (xc) functional, PBE [41], which has been found insufficient to describe aqueous systems at ambient conditions. However, our previous studies showed that the PBE functional works better at extreme P-T conditions than at ambient conditions $[21,27,42]$. For example, for $\mathrm{CO}_{2}$ dissolved in supercritical water at $\sim 11 \mathrm{GPa}$ and $1000 \mathrm{~K}$, PBE predicts similar carbon species concentrations to those obtained by PBE0, a hybrid 
xc functional [43]. Spanu et al. also validated the accuracy of free energy calculations for hydrocarbons using PBE [40]. Note that the long-range dispersion interactions are missing in both $\mathrm{PBE}$ and $\mathrm{PBE} 0$, but here the chemical reactions involve breaking and forming of covalent bonds, in which weak van der Waals interactions do not play a major role.

Overall, our AIMD simulations and free energy calculations show that formic acid is not a short-lived reaction intermediate in the water-gas shift reaction, but a thermodynamically favored product at P-T conditions typically found in Earth's upper mantle.

\section{DISCUSSION}

Formic acid and formate have been found in natural waters in some shallow crustal environments, such as spring waters, fluids in sedimentary basin and hydrothermal fluids, where pressure is lower than $50 \mathrm{MPa}$ and temperature is up to about $673 \mathrm{~K}$ [44, 45]. At high $\mathrm{P}-\mathrm{T}$ or in the presence of catalysts, formic acid may decompose through the decarboxylation reaction [46]:

$$
\mathrm{HCOOH} \rightarrow \mathrm{CO}_{2}+\mathrm{H}_{2}
$$

or the dehydration reaction:

$$
\mathrm{HCOOH} \rightarrow \mathrm{CO}+\mathrm{H}_{2} \mathrm{O}
$$

Previous studies found that the decarboxylation reaction predominates in aqueous environments, while dehydration happens more in gas phases $[45,46]$. Thus, formic acid or formate has often been viewed as a reaction intermediate in the abiotic reduction of oxidized carbon to hydrocarbons or in the decomposition of bigger organic molecules. In the laboratory, as it is more convenient to load liquids to a reaction cell, some experiments started from $\mathrm{HCOOH}(\mathrm{l})$ to generate a mixture of $\mathrm{CO}_{2}, \mathrm{H}_{2}, \mathrm{CO}$ and $\mathrm{H}_{2} \mathrm{O}$ through reaction (5) and (6) $[18,47]$.

With increasing P and T in Earth's upper mantle, traditional geochemical models for C-HO fluids focused on simple mixtures of small volatile molecules, such as $\mathrm{H}_{2} \mathrm{O}, \mathrm{CO}_{2}, \mathrm{CO}, \mathrm{C}_{2} \mathrm{H}_{6}$, 
$\mathrm{H}_{2}, \mathrm{O}_{2}$ [19], whereas recent first-principles simulations, geochemical models, and high P-T experiments suggest that fully oxidized carbon may largely exist as $\mathrm{HCO}_{3}^{-}$and $\mathrm{CO}_{3}^{2-}$ ions, and $\mathrm{H}_{2} \mathrm{CO}_{3}(\mathrm{aq})$ in water, not only non-interactive $\mathrm{CO}_{2}(\mathrm{aq})$ molecules [26-29]. In Earth's mantle, the oxygen fugacity, $f_{\mathrm{O}_{2}}$, reflects the mantle oxidation state, which greatly influences the speciation of C-H-O fluids. With increasing depth, $f_{\mathrm{O}_{2}}$ generally decreases, so the upper mantle likely becomes more reducing at the bottom [30]. Contrary to the commonly accepted assumption that the water-gas shift reaction may adjust the composition of C-H-O fluids in a reducing environment $[18,31]$, we found $\mathrm{CO}$ may react with $\mathrm{H}_{2} \mathrm{O}$ to generate formic acid, which is a thermodynamically stable product. Thus, formic acid or formate may be an important reduced carbon carrier in C-H-O fluids in Earth's upper mantle, and participates in many geochemical processes.

In our simulations, formic acid can easily dissociate in water at extreme P-T conditions as shown in Fig. 3. For example, in a 0.94 molal solution of $\mathrm{HCOOH}(\mathrm{aq})$ at $\sim 13 \mathrm{GPa}$ and $1400 \mathrm{~K}$, the concentration of $\mathrm{H}_{3} \mathrm{O}^{+}(\mathrm{aq})$ is $\sim 0.58$ molal larger than that of $\mathrm{OH}^{-}(\mathrm{aq})$, so the presence of $\mathrm{HCOOH}(\mathrm{aq})$ greatly affects the acidity of aqueous solutions in a reducing environment and may influence water-rock interactions in deep Earth [48]. It was recently reported that infiltrating $\mathrm{C}-\mathrm{H}-\mathrm{O}$ fluids may dissolve a great amount of carbonate minerals in subducting slabs, and bring carbon back to magmas, which may be finally released as $\mathrm{CO}_{2}$ from volcanoes $[49,50]$; however, we have not yet known the chemical mechanism of this dissolution. It is possible that reduced carbon forms formic acid, which helps to dissolve carbonate minerals into C-H-O fluids in the deep carbon cycle. The dissociation of formic acid could also promote the formation of metal-formate, i.e. organometallic, complexes in upper mantle fluids [23].

Formic acid or formate may also participate into the formation of diamonds in Earth's upper mantle, as indicated by the newly developed Deep Earth Water (DEW) model $[6,8]$ and experiments [7]. Sverjensky and Huang found that the diamond formation may be associated with a $\mathrm{pH}$ drop, and most of precipitated diamonds come from the destruction 
of formate [6]:

$$
\mathrm{HCOO}^{-}(\mathrm{aq})+\mathrm{H}^{+}(\mathrm{aq})+\mathrm{H}_{2}(\mathrm{aq}) \rightarrow \mathrm{C}(\text { diamond })+2 \mathrm{H}_{2} \mathrm{O}
$$

In the formation of diamonds from the Panda kimberlite, formate contributes to 2.2 out of $13.8 \mathrm{~mol}$ of carbon in diamonds [8]:

$$
3 \mathrm{HCOO}^{-}(\mathrm{aq})+3 \mathrm{H}^{+}(\mathrm{aq})+\mathrm{C}_{2} \mathrm{H}_{6}(\mathrm{aq}) \rightarrow 5 \mathrm{C}(\text { diamond })+6 \mathrm{H}_{2} \mathrm{O} \text {. }
$$

Using Raman spectroscopy measurements, Frezzotti found the surfaces of diamonds in metamorphic rocks from Lago di Cignana in Italy are coated by functional groups of carboxylic acids, indicating that organic acids play an important role in nucleation and growth of diamonds in deep Earth [7].

\section{CONCLUSIONS}

In summary, we performed extensive AIMD simulations and free energy calculations to study the water-gas shift reaction at extreme P-T conditions found in Earth's upper mantle. We found that $\mathrm{CO}$ directly reacts with $\mathrm{H}_{2} \mathrm{O}$ to generate formic acid at 10 13 GPa and $1400 \mathrm{~K}$ without any catalyst. $\mathrm{HCOOH}(\mathrm{aq})$ dissociates frequently in supercritical water and greatly affects the $\mathrm{pH}$ of the solutions. It is commonly assumed that $\mathrm{HCOOH}$ or $\mathrm{HCOO}^{-}$is an intermediate product and will finally decompose in the water-gas shift reaction; however, our free energy calculations based on the AIMD simulation trajectories show that $\mathrm{HCOOH}$ is thermodynamically more favored than the mixture of $\mathrm{CO}_{2}$ and $\mathrm{H}_{2}$ above $3 \mathrm{GPa}$ and at 1000 1400 K.

Our study suggests that formic acid or formate may be an important reduced carbon carrier in the deep carbon cycle. The presence of $\mathrm{HCOOH}(\mathrm{aq})$ increases the acidity of aqueous geofluids, and helps to dissolve carbonate minerals. C-H-O fluids may carry $\mathrm{HCOO}^{-}$, $\mathrm{CO}_{3}^{2-}, \mathrm{HCO}_{3}^{-}, \mathrm{H}_{2} \mathrm{CO}_{3}(\mathrm{aq}), \mathrm{CO}_{2}(\mathrm{aq})$ etc. into magmas, which may decompose near Earth's

surface and be finally released as $\mathrm{CO}_{2}$ from volcanoes. Formate may also be a key reactant 
in the formation of diamonds in the mantle. The stability of formic acid at P-T conditions in Earth's upper mantle suggests that Fischer-Tropsch-type synthesis in deep Earth may differ dramatically from hydrocarbon synthesis at industrial P-T conditions or in shallow Earth environments. Our findings highlight the diversity of aqueous carbon species in C-H-O geofluids and the importance of organic geochemistry at extreme conditions.

\section{METHODS}

We performed AIMD simulations within the Born-Oppenheimer approximation using the Qbox code (http://qboxcode.org/) [51]. We used the PBE exchange-correlation functional [41] and plane-wave basis sets with periodic boundary conditions. We used norm-conserving pseudopotentials $[52,53]$ and employed a kinetic energy cutoff of $85 \mathrm{Ry}$, which was increased to 145 Ry to compute pressure. The Brillouin zone was sampled at the $\Gamma$-point only. We used deuterium instead of hydrogen in the simulations, allowing for a larger time step (0.24 fs). We still refer to these atoms as hydrogen atoms in the main text for convenience. The temperature was controlled by stochastic rescaling of the velocities with a damping factor of $24.2 \mathrm{fs}$ [54]. After an equilibration of at least 5 ps at each P-T condition, we ran AIMD simulations of $\sim 300 \mathrm{ps}$ long to detect chemical reactions (see Table SI in the supporting information).

To determine the carbon species in our AIMD simulations of $\mathrm{CO}(\mathrm{aq})$, we analyzed the atomic trajectories in each frame and searched for the three nearest $\mathrm{O}$ atoms to the $\mathrm{C}$ atom, whose distances are $d_{C-O 1}, d_{C-O 2}$, and $d_{C-O 3}$ from small to large. If $d_{C-O 2}$ is larger than $d_{C-O 1}$ by more than $0.4 \AA$, the molecule is considered as $\mathrm{CO}$; otherwise the $\mathrm{C}$ atom is bonded with at least two $\mathrm{O}$ atoms, and additionally if $d_{\mathrm{C}-\mathrm{O} 3}-d_{\mathrm{C}-\mathrm{O} 2}<0.4 \AA$, the $\mathrm{C}$ atom is bonded with three $\mathrm{O}$ atoms. $\mathrm{H}$ atoms were considered bonded to their nearest-neighbor $\mathrm{C}$ or $\mathrm{O}$ atom. Using this method, we may distinguish $\mathrm{CO}, \mathrm{HCOOH}, \mathrm{HCOO}^{-}, \mathrm{HCOOH}_{2}^{+}$, $\mathrm{HC}(\mathrm{OH})_{3}$, and orthoformic acid derivatives. 
We used the two-phase thermodynamic model introduced in Ref. [37-39] to calculate the free energies of reactants and products. In this method, entropy is divided into translational, rotational, and vibrational parts, which were obtained from corresponding phonon densities of states (DOS). The translational and rotational phonon DOS contain solid-like and gas-like parts. The phonon DOS were calculated by the Fourier transform of velocity auto-correlation functions from AIMD trajectories, each of which is at least 20 ps long. In case proton transfer

occurs, the contribution of the $i$ th chemical species to the total entropy is weighted by $\frac{\tau_{i}}{t_{t o t}}$, where $\tau_{i}$ is its life time and $t_{t o t}$ is the total simulation time [55].

\section{DATA AVAILABILITY}

The data that support this study are available upon request from the authors.

\section{CODE AVAILABILITY}

Qbox is a free and open source code available at http://qboxcode.org. Data processing scripts are available upon request from the authors.

\section{ACKNOWLEDGEMENTS}

N.S. acknowledges the Hong Kong Ph.D. Fellowship Scheme. D.A.S. acknowledges funding for DAS from the US DOE (DE-FG-02-96ER-14616) and NSF (EAR 1624325). D.P. acknowledges support from the Croucher Foundation through the Croucher Innovation Award, the Hong Kong Research Grants Council (Project Nos. ECS-26305017 and GRF-16307618), the National Natural Science Foundation of China (Project No. 11774072 and Excellent Young Scientists Fund). This research was supported by the Alfred P. Sloan Foundation through the Deep Carbon Observatory. 


\section{AUTHOR CONTRIBUTIONS}

D.P. designed the research. N.S. and Z.C. performed the AIMD simulations. N.S. analyzed the AIMD trajectories. J.Y., N.S., and Z.C. did the free energy calculations. N.S. and D.P. wrote the manuscript. All authors contributed to the analysis and discussion of the data and the writing of the manuscript.

* These authors contributed equally to this work.

$\dagger$ dingpan@ust.hk

[1] Falkowski, P. et al. The global carbon cycle: A test of our knowledge of Earth as a system. Science 290, 291-296 (2000).

[2] Hazen, R. M. \& Schiffries, C. M. Why deep carbon? Rev. Mineral. Geochem. 75, 1-6 (2013).

[3] Mendeleev, D. L'origine du pétrole. Revue Scientifique 13, 409-416 (1877).

[4] McCollom, T. M. Laboratory simulations of abiotic hydrocarbon formation in Earth's deep subsurface. Rev. Mineral. Geochem. 75, 467-494 (2013).

[5] Sephton, M. A. \& Hazen, R. M. On the origins of deep hydrocarbons. Rev. Mineral. Geochem. 75, 449-465 (2013).

[6] Sverjensky, D. A. \& Huang, F. Diamond formation due to a $\mathrm{pH}$ drop during fluid-rock interactions. Nat. Commun. 6, 8702 (2015).

[7] Frezzotti, M. L. Diamond growth from organic compounds in hydrous fluids deep within the Earth. Nat. Commun. 10, 4952 (2019).

[8] Huang, F. \& Sverjensky, D. A. Mixing of carbonatitic into saline fluid during panda diamond formation. Geochim. Cosmochim. Acta 284, 1-20 (2020).

[9] Sobolev, N. V. et al. Mineral and fluid inclusions in diamonds from the Urals placers, Russia: Evidence for solid molecular $\mathrm{N}_{2}$ and hydrocarbons in fluid inclusions. Geochim. Cosmochim. 
Acta 266, 197-219 (2019).

[10] Daniel, I., Oger, P. \& Winter, R. Origins of life and biochemistry under high-pressure conditions. Chem. Soc. Rev. 35, 858-875 (2006).

[11] Frost, D. J. The Upper Mantle and Transition Zone. Elements 4, 171-176 (2008).

[12] Lobanov, S. S. et al. Carbon precipitation from heavy hydrocarbon fluid in deep planetary interiors. Nat. Commun. 4, 2446 (2013).

[13] Dry, M. E. The Fischer-Tropsch process: 1950-2000. Catal. Today 71, 227-241 (2002).

[14] Bukur, D. B., Todic, B. \& Elbashir, N. Role of water-gas-shift reaction in Fischer-Tropsch synthesis on iron catalysts: A review. Catal. Today 275, 66-75 (2016).

[15] Ratnasamy, C. \& Wagner, J. Water gas shift catalysis. Catal. Rev. 51, 325-440 (2009).

[16] Shido, T. \& Iwasawa, Y. Reactant-promoted reaction mechanism for water-gas shift reaction on Rh-doped $\mathrm{CeO}_{2}$. J. Catal. 141, 71-81 (1993).

[17] Yoshida, K., Wakai, C., Matubayasi, N. \& Nakahara, M. NMR spectroscopic evidence for an intermediate of formic acid in the water-gas-shift reaction. J. Phys. Chem. A 108, 7479-7482 (2004).

[18] Sharma, A., Cody, G. D. \& Hemley, R. J. In situ diamond-anvil cell observations of methanogenesis at high pressures and temperatures. Energy Fuels 23, 5571-5579 (2009).

[19] Zhang, C. \& Duan, Z. A model for C-O-H fluid in the Earth's mantle. Geochim. Cosmochim. Acta 73, 2089-2102 (2009).

[20] Manning, C. E., Shock, E. L. \& Sverjensky, D. The chemistry of carbon in aqueous fluids at crustal and upper mantle conditions: Experimental and theoretical constraints. Rev. Mineral. Geochem. 75, 109-148 (2013).

[21] Pan, D., Spanu, L., Harrison, B., Sverjensky, D. A. \& Galli, G. Dielectric properties of water under extreme conditions and transport of carbonates in the deep Earth. Proc. Natl. Acad. Sci. U.S.A. 110, 6646-6650 (2013). 
[22] Sverjensky, D. A., Stagno, V. \& Huang, F. Important role for organic carbon in subductionzone fluids in the deep carbon cycle. Nat. Geosci. 7, 909-913 (2014).

[23] Huang, F. \& Sverjensky, D. A. Extended Deep Earth Water Model for predicting major element mantle metasomatism. Geochim. Cosmochim. Acta 254, 192-230 (2019).

[24] Sverjensky, D. A. Thermodynamic modelling of fluids from surficial to mantle conditions. $J$. Geol. Soc. 176, 348-374 (2019).

[25] Sverjensky, D. A., Daniel, I. \& Brovarone, A. V. The changing character of carbon in fluids with pressure: Organic geochemistry of Earth's upper mantle fluids. In Manning, C. E., Lin, J.-F. \& Mao, W. L. (eds.) Carbon in Earth's Interior, chap. 22, 259-269 (John Wiley \& Sons, Inc, 2020).

[26] Facq, S., Daniel, I., Montagnac, G., Cardon, H. \& Sverjensky, D. A. In situ Raman study and thermodynamic model of aqueous carbonate speciation in equilibrium with aragonite under subduction zone conditions. Geochim. Cosmochim. Acta 132, 375-390 (2014).

[27] Pan, D. \& Galli, G. The fate of carbon dioxide in water-rich fluids under extreme conditions. Sci. Adv. 2, e1601278 (2016).

[28] Abramson, E. H., Bollengier, O. \& Brown, J. M. The water-carbon dioxide miscibility surface to $450{ }^{\circ} \mathrm{C}$ and 7 GPa. Am. J. Sci. 317, 967-989 (2017).

[29] Stolte, N. \& Pan, D. Large presence of carbonic acid in $\mathrm{CO}_{2}$-rich aqueous fluids under Earth's mantle conditions. J. Phys. Chem. Lett. 10, 5135-5141 (2019).

[30] Frost, D. J. \& McCammon, C. A. The redox state of Earth's mantle. Annu. Rev. Earth Planet. Sci. 36, 389-420 (2008).

[31] McCollom, T. M. \& Seewald, J. S. Carbon isotope composition of organic compounds produced by abiotic synthesis under hydrothermal conditions. Earth Planet. Sci. Lett. 243, 74-84 (2006).

[32] Gygi, F. \& Galli, G. Ab initio simulation in extreme conditions. Mater. Today 8, 26-32 (2005). 
[33] Melius, C. F., Bergan, N. E. \& Shepherd, J. E. Effects of water on combustion kinetics at high pressure. Symp. (Int.) Combust. 23, 217-223 (1991).

[34] Hou, R., Quan, Y. \& Pan, D. Dielectric constant of supercritical water in a large pressuretemperature range. J. Chem. Phys 153, 101103 (2020).

[35] Tro, N. J. Chemistry: a molecular approach (https://chem.libretexts.org/, 2020).

[36] Álvarez, A. et al. Challenges in the greener production of formates/formic acid, methanol, and DME by heterogeneously catalyzed $\mathrm{CO}_{2}$ hydrogenation processes. Chem. Rev. 117, 9804-9838 (2017).

[37] Lin, S.-T., Blanco, M. \& Goddard, W. A. The two-phase model for calculating thermodynamic properties of liquids from molecular dynamics: Validation for the phase diagram of LennardJones fluids. J. Chem. Phys. 119, 11792-11805 (2003).

[38] Lin, S.-T., Maiti, P. K. \& Goddard, W. A. Two-pase thermodynamic model for efficient and accurate absolute entropy of water from molecular dynamics simulations. J. Phys. Chem. B 114, 8191-8198 (2010).

[39] Lai, P. K., Hsieh, C.-M. \& Lin, S.-T. Rapid determination of entropy and free energy of mixtures from molecular dynamics simulations with the two-phase thermodynamic model. Phys. Chem. Chem. Phys. 14, 15206-15213 (2012).

[40] Spanu, L., Donadio, D., Hohl, D., Schwegler, E. \& Galli, G. Stability of hydrocarbons at deep Earth pressures and temperatures. Proc. Natl. Acad. Sci. U.S.A. 108, 6843-6846 (2011).

[41] Perdew, J. P., Burke, K. \& Ernzerhof, M. Generalized gradient approximation made simple. Phys. Rev. Lett. 77, 3865-3868 (1996).

[42] Pan, D., Wan, Q. \& Galli, G. The refractive index and electronic gap of water and ice increase with increasing pressure. Nat. Commun. 5, 3919 (2014).

[43] Adamo, C. \& Barone, V. Toward reliable density functional methods without adjustable parameters: The PBE0 model. J. Chem. Phys. 110, 6158-6170 (1999). 
[44] Zeng, Y. \& Liu, J. Short-chain carboxylates in fluid inclusions in minerals. Appl. Geochem. 15, $13-25(2000)$.

[45] McCollom, T. M. \& Seewald, J. S. Experimental constraints on the hydrothermal reactivity of organic acids and acid anions: I. Formic acid and formate. Geochim. Cosmochim. Acta 67, 3625-3644 (2003).

[46] Yu, J. \& Savage, P. E. Decomposition of formic acid under hydrothermal conditions. Ind. Eng. Chem. Res. 37, 2-10 (1998).

[47] Seewald, J. S., Zolotov, M. Y. \& McCollom, T. M. Experimental investigation of single carbon compounds under hydrothermal conditions. Geochim. Cosmochim. Acta 70, 446-460 (2006).

[48] Galvez, M. E., Connolly, J. A. D. \& Manning, C. E. Implications for metal and volatile cycles from the pH of subduction zone fluids. Nature 539, 420-424 (2016).

[49] Ague, J. J. \& Nicolescu, S. Carbon dioxide released from subduction zones by fluid-mediated reactions. Nat. Geosci. 7, 355-360 (2014).

[50] Manning, C. E. A piece of the deep carbon puzzle. Nature Geosci. 7, 333-334 (2014).

[51] Gygi, F. Architecture of Qbox: A scalable first-principles molecular dynamics code. IBM J. Res. Dev. 52, 137-144 (2008).

[52] Hamann, D. R., Schlüter, M. \& Chiang, C. Norm-conserving pseudopotentials. Phys. Rev. Lett. 43, 1494-1497 (1979).

[53] Vanderbilt, D. Optimally smooth norm-conserving pseudopotentials. Phys. Rev. B 32, 84128415 (1985).

[54] Bussi, G., Donadio, D. \& Parrinello, M. Canonical sampling through velocity rescaling. J. Chem. Phys. 126, 014101 (2007).

[55] Caro, M. A., Lopez-Acevedo, O. \& Laurila, T. Redox potentials from ab initio molecular dynamics and explicit entropy calculations: Application to transition metals in aqueous solution. J. Chem. Theory Comput. 13, 3432-3441 (2017). 
[56] Flyvbjerg, H. \& Petersen, H. G. Error estimates on averages of correlated data. J. Chem. Phys. 91, 461-466 (1989). 

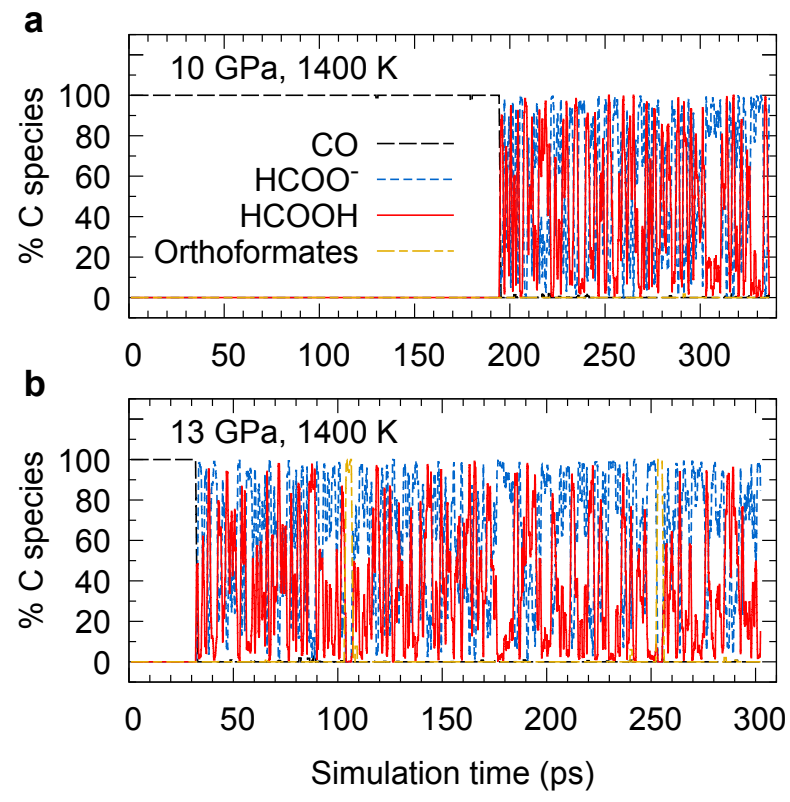

FIG. 1. Mole percents of $\mathrm{CO}(\mathrm{aq}), \mathrm{HCOO}^{-}(\mathrm{aq}), \mathrm{HCOOH}(\mathrm{aq})$, and orthoformates as functions of simulation time in AIMD simulations. Initially, 0.93 molal $\mathrm{CO}(\mathrm{aq})$ was dissolved in supercritical water. Two P-T conditions, (a) $10 \mathrm{GPa}, 1400 \mathrm{~K}$ and (b) $13 \mathrm{GPa}, 1400 \mathrm{~K}$, were compared. Orthoformates include orthoformic acid $\left(\mathrm{HC}(\mathrm{OH})_{3}(\mathrm{aq})\right)$ and its conjugate bases $\left(\mathrm{CH}_{3} \mathrm{O}_{3}^{-}(\mathrm{aq}), \mathrm{CH}_{2} \mathrm{O}_{3}^{2-}(\mathrm{aq})\right.$, $\left.\mathrm{CHO}_{3}^{3-}(\mathrm{aq})\right)$. The mole percents were calculated by 1-ps moving average.

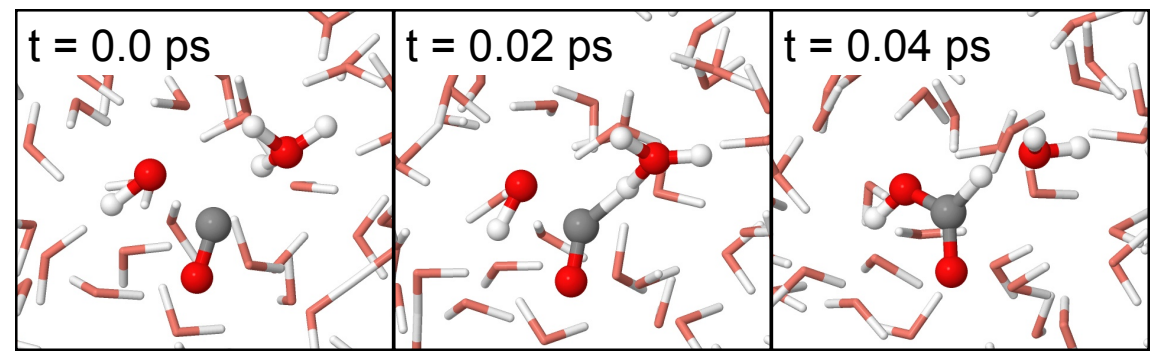

FIG. 2. Formation of formic acid from $\mathrm{CO}(\mathrm{aq})$ at $\sim 10 \mathrm{GPa}, 1400 \mathrm{~K}$. The carbon atom formed a new $\mathrm{C}-\mathrm{O}$ bond with the oxygen atom from a $\mathrm{OH}^{-}$ion, and almost simultaneously a $\mathrm{H}_{3} \mathrm{O}^{+}$ion donated a proton to the carbon atom. 


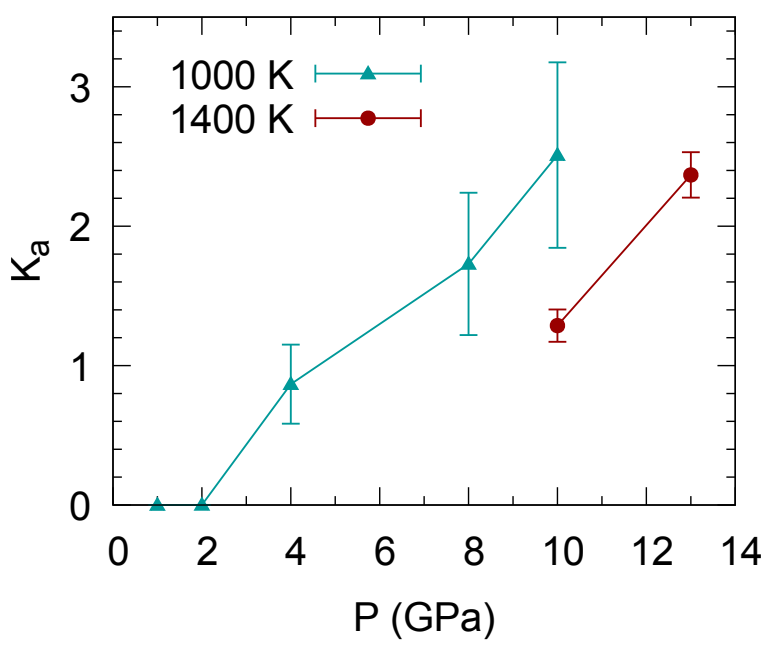

FIG. 3. Acid dissociation constant of $\mathrm{HCOOH}(\mathrm{aq}), K_{a}=\frac{\left[\mathrm{HCOO}^{-}\right]\left[\mathrm{H}^{+}\right]}{\left[\mathrm{HCOOH}^{2}\right.}$, as a function of pressure at 1000 and 1400 K. Error bars were obtained using the blocking method [56]. The lines connecting points are a guide to the eye. 

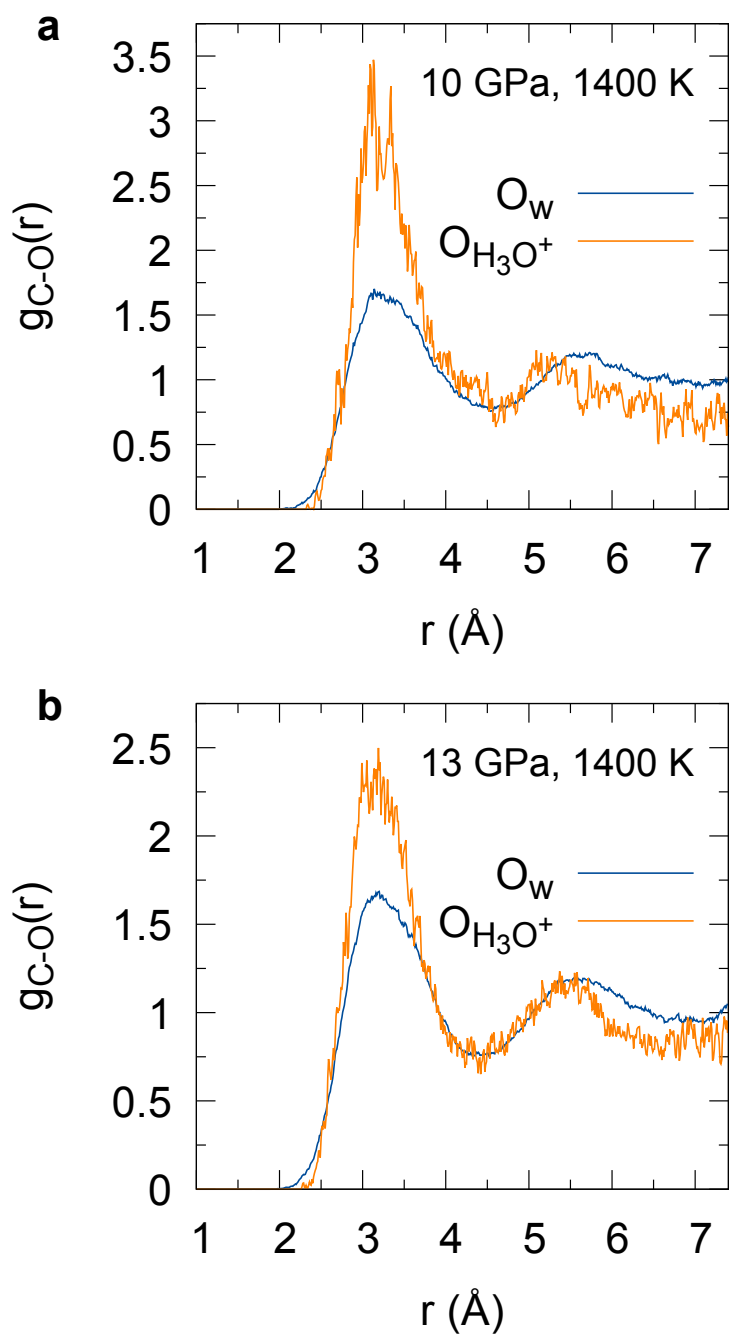

FIG. 4. Radial distribution functions of the carbon atom of formate versus oxygen atoms of $\mathrm{H}_{2} \mathrm{O}$ $\left(\mathrm{O}_{w}\right)$ or $\mathrm{H}_{3} \mathrm{O}^{+}(\mathrm{aq})\left(\mathrm{O}_{\mathrm{H}_{3} \mathrm{O}^{+}}\right)$. The molality of $\mathrm{HCOO}^{-}(\mathrm{aq})$ is 0.94 molal. Two P-T conditions, (a) $\sim 10 \mathrm{GPa}, 1400 \mathrm{~K}$ and $(\mathrm{b}) \sim 13 \mathrm{GPa}, 1400 \mathrm{~K}$, were compared. 

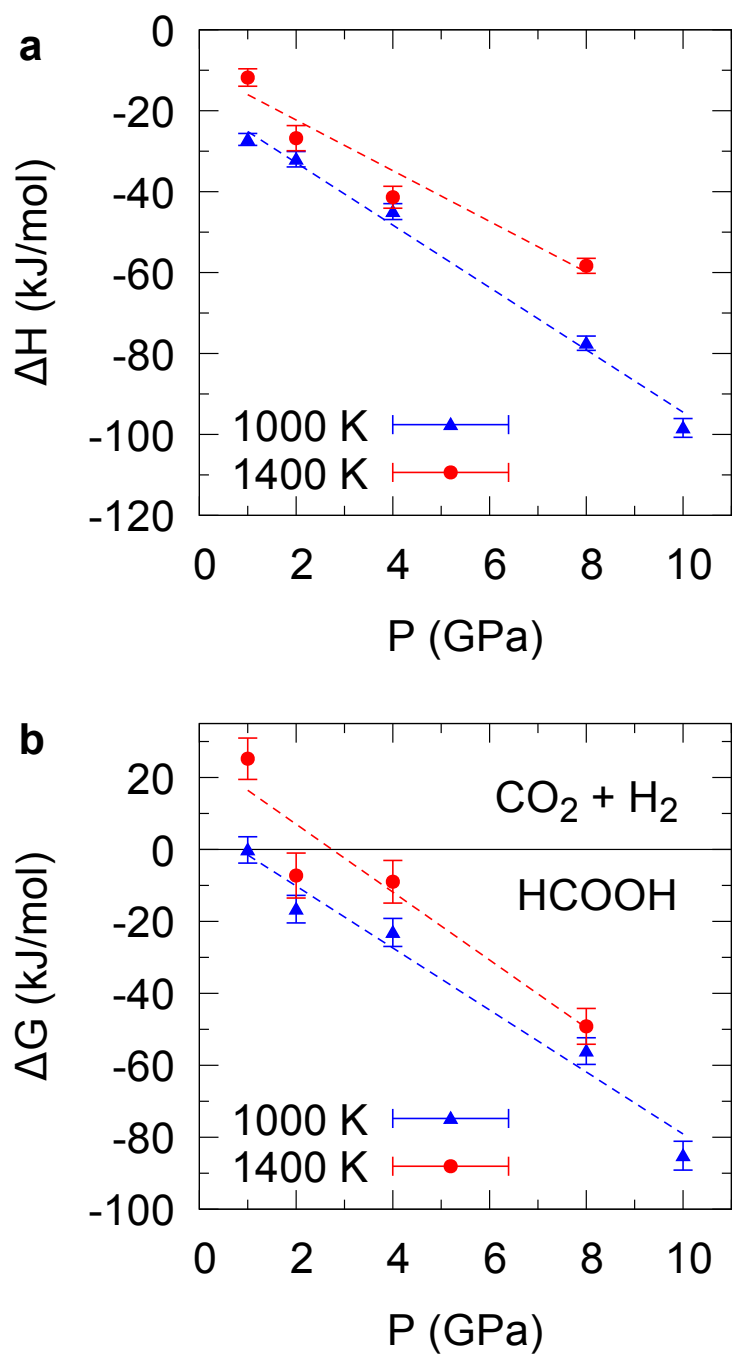

FIG. 5. Reaction enthalpies (a) and free energies (b) of the formation of $\mathrm{HCOOH}$ from $\mathrm{CO}_{2}$ and $\mathrm{H}_{2}$ as functions of pressure. Two temperatures were compared: 1000 and $1400 \mathrm{~K}$. Error bars were obtained using the blocking method [56]. Dashed lines show the linear fit of first-principles data. 